\title{
Peertechz
}

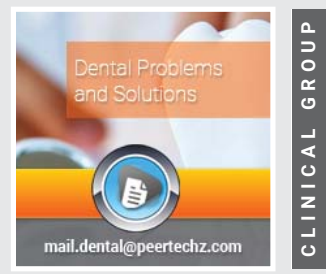

\section{Correlation Between Cranial Base Morphology and Skeletal Maloclusion in a Sample of Sudanese Orthodontic Patients}

\section{Alaa Abd Elgadir Ahmed ${ }^{1}$ and Amal Hussein Abuaffan ${ }^{2 *}$}

${ }^{1}$ Lecture, Department of Orthodontics, University of Khartoum, Khartoum, Sudan

${ }^{2}$ Department of Orthodontics, University of Khartoum, Khartoum, Sudan
Received: 22 October, 2020

Accepted: 10 November, 2020

Published: 17 November, 2020

*Corresponding author: Amal Hussein Abuaffan, Department of Orthodontics, University of Khartoum, Khartoum, Sudan, Tel: 00249 912914556;

E-mail: amalabuaffan@yahoo.com

ORCID: https://orcid.org/0000-0001-7014-4147 Keywords: Malocclusion; Cranial base; Sudanese https://www.peertechz.com

\section{Check for updates}

\begin{abstract}
Objective: This study aimed to evaluate the relationship between the cranial base and jaw base in a sample of Sudanese orthodontic patients

Material and methods: one hundred and twenty lateral Cephalograms from university of Khartoum orthodontic department archive 60 males, 60 females, age $18.3 \pm$ 4.3 years old, were classified into 3 sagittal malocclusion groups (40 individuals each) according to their ANB angle. A cephalometric analysis of the study variables of the cranial base (NSBa, N-S, S-Ba, N-Ba) and jaws bases (SNA, SNB, ANB, A-Co, Gn-Co) was carried out, the morphological characteristics of the cranial and jaw bases in the three groups were compared using One-way ANOVA test and Pearson's coefficient correlation analysis.
\end{abstract}

Results: Cranial base angle and cranial base lengths did not show significant differences between the main classes of malocclusion studied. However, jaw size was statistically significant different between the 3 groups, longer maxilla was found in Class II group and the mandible was longer in Class III group. Strong significant relation was found between SNA, SNB and NSBa in the three groups. Positive correlation was found between cranial base lengths and maxillary and mandibular lengths among the three groups.

Conclusion: Cranial base angulation and lengths has no major role in developing malocclusion.

\section{Introduction}

The facial prognathism and cranial base flexion relationship has long been of concern to orthodontists, orthognathic and plastic surgeons.

As early as 1916, Young suggested a probable association between the morphology of the cranial base and jaws prognathism [1].

Brodie emphasized the importance of studying the cranial base growth and development for orthodontists, since the successful malocclusions diagnosis and treatment depends, largely, on the growth of entire craniofacial region [2].

Bjork stated that "the cranial base mainly develops from the chondrocranium, and its shape varies considerably during development. Until birth it tend to be flat, which gradually flexing through the first years of life until ten years old approximately, when it reached its final shape" [3].
The cranial base composed of different bones (Frontal, Ethmoid, Sphenoid, Temporal, Parietal, and Occipital) it forms the cranial vault floor and interconnected by Synchondrosis, it extends from the foramen caecum anteriorly to the occipital bone posteriorly, Sella turcica divides the cranial base into anterior (Sella to Nasion) and posterior (Sella to Basion or Sella to Articulare) limbs, the two limbs form a flexion at Sella forming cranial base angle [4].

The maxilla is joined to the anterior segment and the mandible to the posterior segment. Consequently, it is possible that any alter in flexion would change maxillary and mandibular positions relation to the cranial base along with to each other. This in turn may influence the skeletal pattern and type of malocclusion [5].

Enlow in 1993 assumed the cranial base as the template for the development of the face. So alteration in cranial base length and angulation directly affects the structure, the size, 
the angles, and positioning of the parts of the face. According to Enlow, the increase in the cranial base angle causes a retrusive effect on the mandible, and its reduction, a protrusive effect [6].

Hopkin et al, in a series of related studies described a linear relationship between the cranial base angle (using Articulare to represent the posterior limit of the cranial base) and jaws prognathism with the angle systematically reducing from Class II, via Class I, to Class III individuals [7].

Basicranial morphology, and other different factors like soft tissue stretching and the posture of head and neck are thought to influence the development of a skeletal malocclusion [8].

The influence of cranial base morphology as an etiological factor of sagittal jaw discrepancies is still a matter of debate. Therefore, the aim of the present study was to investigate the correlation between the cranial base morphology and sagittal skeletal malocclusions in a sample of Sudanese orthodontic patients.

\section{Material and methods}

This was a cross sectional study in which pretreatment cephalometric radiographs of orthodontic patient's records in department of orthodontics at university of Khartoum were used as study population.

For this study the inclusion criteria were as follow: A Sudanese nationality Patient of more than 15 years of age and the radiographs were of good quality and obtained from the same standard machine.

While the exclusion criteria were: history of previous or active orthodontic treatment, presence of congenital deformities and poor quality images or images with positional errors

\section{Data collection tools and technique}

All patients' records in the department of orthodontics university of Khartoum from 2016-2018 had been examined, then the data were classified into 3 skeletal groups (Class I, II and III) based on ANB angle:

Class I: ANB range of $\left(2^{\circ}\right.$ to $\left.4^{\circ}\right)$

Class II: ANB angle more than $4^{\circ}$

Class III: ANB angle less than $2^{\circ}$.

Then 120 cephalometric radiographs (40 radiograph each group) that fulfilled the inclusion criteria had been randomly selected.

All lateral Cephalograms were taken on a digital machine (PROMAX 3D.D-054SB-C, 2014, PLANMECA OY, 00880 Helsinki, Finland) in natural head position.

Later, all cephalometric soft copies were traced and analyzed by the computer using cephalometric analysis Software (vista Dent $\mathrm{OC}^{\mathrm{TM}}$ - version 4.2.61 (177) 2006 - GAC International).
All the tracing and measurement were carried out by the main investigator and the study variables were transferred to data collection sheet.

The variables analyzed were

\section{Cranial base parameters Figure 1:}

Anterior cranial base length: Nasion-Sella (N-S)

Posterior cranial base length: Sella-Basion (S-Ba)

Total cranial base length: Nasion-Basion (N-Ba)

Cranial base angle: Nasion-Sella-Basion (NSBa)

Linear measurements: S-N (Sella Nasion), S-Ba (SellaBasion), Ba-N (Basion -Nasion)

Angular measurements: SNBa (Sella-Nasion-Basion).

Maxillary and mandibular skeletal parameters: Figure 2.

Sagittal relation of maxilla to cranial base: Sella-NasionPoint A (SNA)

Sagittal relation of mandible to cranial base: Sella-NasionPoint B (SNB)

Maxillary mandibular sagittal relationship: point ANasion- Point B (ANB)

Maxillary length: Point A-Condylon (A-Co)

Mandibular length: Menton-Condylon (Me-Co)

Angular measurement: SNA (Sella-Nasion -Point A), SNB (Sella -Nasion -Point B), ANB (Point A- Nasion -Point B)

\section{Statistical analysis}

Statistical analysis was performed using Statistical Package Software System, version 21 (SPSS Inc., Chicago, Illinois).

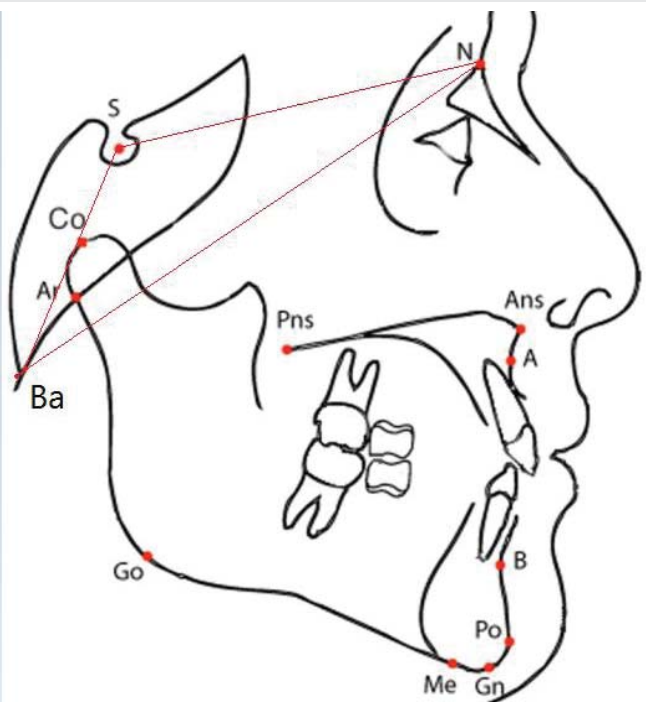

Figure 1: Cranial base measurements.

Citation: Elgadir Ahmed AA, Abuaffan AH (2020) Correlation Between Cranial Base Morphology and Skeletal Maloclusion in a Sample of Sudanese Orthodontic Patients. J Dent Probl Solut 7(2): 090-095. DOI: https://dx.doi.org/10.17352/2394-8418.000091 


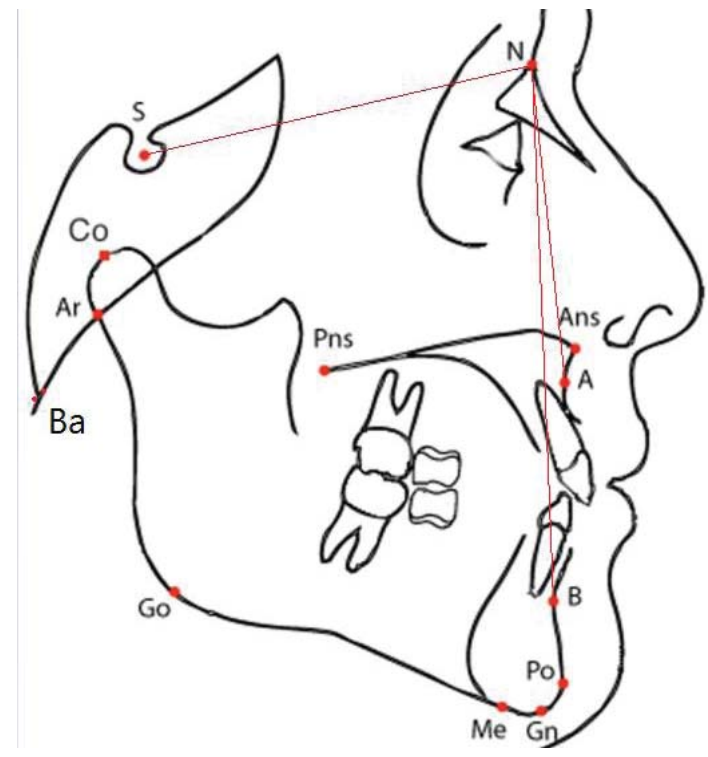

Figure 2: Maxillary and mandibular skeletal parameters.

Descriptive statistics were used to describe data in terms of tables, mean and standard deviation. One-way ANOVA test and Pearson's coefficient correlation analysis were applied to test the reliability and correlation of the study parameters among the various study groups.

For all test a P-value set at the 0.05 level.

\section{Reliability test}

$15 \%$ of the total sample were randomly selected and remeasured by the main investigator after two weeks. T-test were conducted as well as a test for correlation between the two measurements at $\mathrm{P}=0.05$. [9].

\section{Results}

A total of 120 lateral cephalometric radiographs of patients age (18.4 \pm 4.2 SD years) were analyzed, 40 in each Class (I, II and III) classified according to ANB angle.

For all test a P-value set at the 0.05 level.

\section{Reliability test}

Interclass correlation coefficient showed no statistically significant difference between the two readings for all study variables (Table 1).

Table 2 presented the means and standard deviations of cephalometric values for the whole sample and for each subgroup.

It's obvious that no significant difference in the linear $(\mathrm{N}-$ $\mathrm{S}, \mathrm{S}-\mathrm{Ba}, \mathrm{N}-\mathrm{Ba}$ ) and angular (NSBa) measurements between the three groups.

For the cranial base angle, Class II group show the highest value (134.78 \pm 6.29$)$, and Class III cases the lowest value $(131.43 \pm 8.11)$

\section{Correlation between the cranial base angle and jaw base}

In Table 3, noticeable strong significant negative correlation in the sagittal jaw base between NSBa and SNA $(r=-0.395, \mathrm{P}$ $<0.01)$ also between NSBa and SNB $(r=-0.426, \mathrm{P}<0.01)$ in the 3 classes.

\section{Correlation between the cranial base length and jaw base}

(Table 4), it's clear that no significant correlation between linear variables and the sagittal jaw base relationship in the total sample were existed.

Table $5 \mathrm{NBa}$ was related to maxillary length in the whole sample $(\mathrm{r}=0.539, \mathrm{P}<0.01)$, low correlation was seen with mandibular length $(\mathrm{r}=0.366, \mathrm{P}<0.01)$ and $\mathrm{SN}$ with both

Table 1: Interclass reliability test.

\begin{tabular}{|c|c|c|c|c|c|c|c|}
\hline \multicolumn{3}{|c|}{ Variable } & \multicolumn{4}{|c|}{ Interclass correlation } & Sig. \\
\hline \multicolumn{3}{|c|}{ SNA angle \& SNA-R } & \multicolumn{4}{|c|}{0.862} & 0.01 \\
\hline \multicolumn{3}{|c|}{ SNB \& SNB-R } & \multicolumn{4}{|c|}{0.983} & 0.000 \\
\hline \multicolumn{3}{|c|}{ ANB \& ANB-R } & \multicolumn{4}{|c|}{0.858} & 0.000 \\
\hline \multicolumn{3}{|c|}{$N-S \& N-S-R$} & \multicolumn{4}{|c|}{0.966} & 0.000 \\
\hline \multicolumn{3}{|c|}{ S-Ba \& S-Ba -R } & \multicolumn{4}{|c|}{0.876} & 0.021 \\
\hline \multicolumn{3}{|c|}{$\mathrm{N}-\mathrm{Ba} \& \mathrm{~N}-\mathrm{Ba}-\mathrm{R}$} & \multicolumn{4}{|c|}{0.965} & 0.014 \\
\hline \multicolumn{3}{|c|}{ NSBa \& NSBa-R } & \multicolumn{4}{|c|}{0.870} & 0.012 \\
\hline \multicolumn{3}{|c|}{ A-Co \& A-Co -R } & \multicolumn{4}{|c|}{0.899} & 0.000 \\
\hline \multicolumn{3}{|c|}{ Gn-Co \& Gn-Co -R } & \multicolumn{4}{|c|}{0.845} & 0.000 \\
\hline \multicolumn{8}{|c|}{$* P \leq 0.05$ is significant } \\
\hline \multirow[t]{2}{*}{ Variables } & \multicolumn{2}{|c|}{$\begin{array}{c}\text { Skeletal Class I } \\
n=40\end{array}$} & \multicolumn{2}{|c|}{$\begin{array}{c}\text { Skeletal Class II } \\
n=40\end{array}$} & \multicolumn{2}{|c|}{$\begin{array}{c}\begin{array}{c}\text { Skeletal Class III } \\
n=40\end{array}\end{array}$} & \multirow{2}{*}{$\begin{array}{l}\text { P value } \\
\text { (ANOVA) }\end{array}$} \\
\hline & Mean & SD & Mean & SD & Mean & SD & \\
\hline SNA & 81.15 & 3.676 & 83.43 & 4.308 & 80.98 & 4.660 & $0.023^{*}$ \\
\hline SNB & 78.55 & 4.344 & 76.23 & 4.423 & 82.28 & 5.134 & $0.000 *$ \\
\hline ANB & 3.18 & .747 & 7.15 & 1.657 & -1.08 & 2.379 & $0.000 *$ \\
\hline N-S & 63.88 & 3.610 & 64.50 & 3.876 & 65.48 & 3.981 & 0.160 \\
\hline S-Ba & 42.58 & 5.178 & 41.05 & 4.254 & 41.88 & 4.109 & 0.299 \\
\hline $\mathrm{N}-\mathrm{Ba}$ & 96.88 & 7.017 & 97.58 & 7.096 & 97.98 & 4.849 & 0.748 \\
\hline $\mathrm{NSBa}$ & 132.48 & 7.805 & 134.78 & 6.298 & 131.43 & 8.111 & 0.106 \\
\hline A-Co & 81.88 & 5.845 & 84.75 & 4.673 & 82.05 & 5.675 & $0.030 *$ \\
\hline Gn-Co & 108.55 & 7.257 & 108.93 & 6.183 & 117.20 & 7.965 & $0.000 *$ \\
\hline
\end{tabular}

Table 3: Correlation test ( $r$ value) between the cranial base angle and jaw base measurements.

\begin{tabular}{|c|c|c|c|c|}
\hline Variables & $\begin{array}{c}\text { Skeletal } \\
\text { Class I } \\
\mathbf{n = 4 0}\end{array}$ & $\begin{array}{c}\text { Skeletal } \\
\text { Class II } \\
\mathbf{n = 4 0}\end{array}$ & $\begin{array}{c}\text { Skeletal } \\
\text { Class III } \\
\mathbf{n = 4 0}\end{array}$ & $\begin{array}{c}\text { Total } \\
\mathbf{n}=120\end{array}$ \\
\hline NSBa- SNA & $-.411^{\star}$ & $-.424^{\star}$ & $-.534^{*}$ & $-.395^{*}$ \\
\hline NSBa- SNB & $-.319^{*}$ & $-.403^{*}$ & $-.450^{*}$ & $-.426^{*}$ \\
\hline NSBa- ANB & .214 & .043 & .039 & $.200^{*}$ \\
\hline NSBa- A-Co & -0.488 & 0.182 & -0.073 & 0.022 \\
\hline NSBa- Gn-Co & -0.252 & 0.194 & 0.050 & -0.156 \\
\hline$* \mathrm{P} \leq 0.05$ is significant & & & & \\
\hline
\end{tabular}

Citation: Elgadir Ahmed AA, Abuaffan AH (2020) Correlation Between Cranial Base Morphology and Skeletal Maloclusion in a Sample of Sudanese Orthodontic Patients. J Dent Probl Solut 7(2): 090-095. DOI: https://dx.doi.org/10.17352/2394-8418.000091 
Table 4: Correlation test ( $r$ value) between the cranial base length and jaw base measurements.

\begin{tabular}{|c|c|c|c|c|}
\hline Variables & $\begin{array}{c}\text { Skeletal } \\
\text { Class I } \\
\mathbf{n = 4 0}\end{array}$ & $\begin{array}{c}\text { Skeletal } \\
\text { Class II } \\
\mathbf{n = 4 0}\end{array}$ & $\begin{array}{c}\text { Skeletal Class III } \\
\mathbf{n = 4 0}\end{array}$ & $\begin{array}{c}\text { Total } \\
\mathbf{n = 1 2 0}\end{array}$ \\
\hline $\mathrm{NBa}-\mathrm{SNA}$ & -.189 & -.269 & .149 & -.111 \\
\hline $\mathrm{NBa}-\mathrm{SNB}$ & -.220 & -.292 & .174 & -.100 \\
\hline $\mathrm{NBa}-\mathrm{ANB}$ & .161 & .067 & .004 & .000 \\
\hline $\mathrm{SBa}-\mathrm{SNA}$ & .075 & .031 & $.323^{\star}$ & .114 \\
\hline $\mathrm{SBa}-\mathrm{SNB}$ & .003 & -.010 & $.399^{\star}$ & .139 \\
\hline $\mathrm{SBa}-\mathrm{ANB}$ & .159 & .003 & -.061 & -.074 \\
\hline $\mathrm{NS}-\mathrm{SNA}$ & .150 & -.320 & .313 & .038 \\
\hline $\mathrm{NS}-\mathrm{SNB}$ & .034 & -.316 & .263 & .067 \\
\hline $\mathrm{NS}-\mathrm{ANB}$ & -.049 & .060 & -.037 & -.090 \\
\hline
\end{tabular}

*P $\leq 0.05$ is significant

Table 5: Correlation test ( $r$ value) between the cranial base length and jaw base length.

\begin{tabular}{|c|c|c|c|c|}
\hline Variables & $\begin{array}{c}\text { Skeletal } \\
\text { Class I } \\
n=40\end{array}$ & $\begin{array}{c}\text { Skeletal } \\
\text { Class II } \\
n=40\end{array}$ & $\begin{array}{c}\text { Skeletal } \\
\text { Class III } \\
n=40\end{array}$ & $\begin{array}{c}\text { Total } \\
n=120\end{array}$ \\
\hline $\mathrm{NBa}-\mathrm{A}-\mathrm{Co}$ & $.483^{*}$ & $.637^{\star}$ & $.604^{\star}$ & $.539^{*}$ \\
\hline $\mathrm{NBa}-\mathrm{Gn}-\mathrm{Co}$ & $.336^{*}$ & $429^{*}$ & $.454^{*}$ & $.366^{*}$ \\
\hline $\mathrm{SBa}-\mathrm{A}-\mathrm{Co}$ & $.529^{*}$ & $.464^{*}$ & $.316^{*}$ & $.401^{*}$ \\
\hline $\mathrm{SBa}-\mathrm{Gn}-\mathrm{Co}$ & $.426^{*}$ & $.297^{*}$ & $.301^{*}$ & $.292^{*}$ \\
\hline $\mathrm{SN}-\mathrm{A}-\mathrm{Co}$ & $.576^{*}$ & $.617^{\star}$ & $.742^{*}$ & $.613^{*}$ \\
\hline SN - Gn-Co & $.407^{\star}$ & $.537^{\star}$ & $.619^{\star}$ & $.534^{*}$ \\
\hline
\end{tabular}

maxillary length for the whole sample $(r=0.613, \mathrm{P}<0.01)$ and mandibular length $(\mathrm{r}=0.534, \mathrm{P}<0.01)$. SBa showed a correlation with both maxillary length $(r=0,401 \mathrm{P}<0.01)$ and mandibular length $(r=0.292, \mathrm{P}<0.01)$ in the whole sample.

\section{Discussion}

Description and diagnosis of a malocclusion is the primary objective of the orthodontist. The diagnosis can dictate the treatment objectives and treatment mechanics for the patient. Therefore, it is important to find out if an underlying skeletal dysplasia is associated with a dental malocclusion. The location and magnitude of a skeletal dysplasia can influence various treatment decisions.

In this study the cranial base morphology were examined by measuring the cranial base angle and cranial base length using 120 lateral cephalometric radiographs classified into 3 groups according to the ANB angle into Class I, II and III.

The main findings of this study is that no significant correlation between cranial base morphology and developing of sagittal skeletal malocclusion among Sudanese orthodontic patients.

Debate has arisen in the selection of cranial base landmarks, over the use of the Basion (Ba) or the Articulare (Ar). Bjork [3] advocated the use of (Ar) point because it's easier and can better represent on lateral cephalometric radiographs, however, Varjanne and Koski have suggested the use of Basion despite the potential difficulties in identification because of its anatomic significance, and discouraged the use of Articulare because of its remoteness from the cranial base [10].

Interestingly, Bhatia and Leighton found the growth patterns in angles and distances as described by use of Articulare, or Basion to be very similar. Accordingly, in the present study Basion point was chosen as the posterior limit of the cranial base [11].

\section{Cranial base parameters}

The results of the present study did not demonstrate a significant difference among the different groups studied in cranial base angle $(P>0.05)$. Similar findings were obtained by Dhopatkar, Polat, Guilherme Thiesen, Kasai and Almeida $[4,5,8,12,13]$. However, Class II group showed increased cranial base angle $(134.7 \pm 6.3)$ in comparison to Class I $(132.5 \pm 7.8)$ and Class III (131.4 \pm 8.1$)$ groups. In contrast, Dinesh et al, in 2017 found significant differences in cranial base angle between Class II and III among Indian population as cranial base angle was significantly increased in Class II group followed by Class I then Class III group [14].

In this current study no statistically significant differences were observed between the means of the cranial base lengths (NS, SBa, and NBa) between group I, II and III as well.

These findings were in disagreement with the result reported by Patricia V.M. Alves in Brazilian population [15].

Differences between the results obtained from the current study and other researchers may be related, partially, to differences in case selection procedures. The present study cases were classified on the basis of ANB angle. Ashish Dhopatkar selected cases were classified on the basis of the British Standards Institute incisor classification [5], whereas, Kerr and Adams selected cases with more definite criteria i.e., Class II division 1 subjects with overjet $\leq 10 \mathrm{~mm}$ and Class III cases with anterior cross bite [16]. It may also possible to be due to compensations in maxilla-mandibular structures. These compensations can minimize an abnormal cranial base morphological pattern [4]. Therefore, the present results did not support the concept that the cranial base angle, by providing different sagittal articulation of the mandible, is a major factor in establishing the sagittal malocclusion.

\section{Maxillary and mandibular skeletal parameters}

The differences in the sagittal discrepancies among the three groups (I, II and III) in this study can be seen by the variation in SNA, SNB, ANB, maxillary length (A-Co), and the mandibular length (Gn-Co).

In this study the anteroposterior position of the maxilla relative to the cranial base as indicated by SNA angle was significantly protrusive in the Class II group $(\mathrm{P}=0.023)$.

The maxillary length (A-Co) as well showed significant difference between the three groups $(\mathrm{P}=0.030)$ with a higher 
length in Class II subjects $(84.75 \pm 4.67)$ followed by Class III $(82.05 \pm 5.67)$ then Class I group $(81.88 \pm 5.84)$. While mandibular length (Gn-Co) and SNB angle were significantly larger in Class III group $(\mathrm{P}=0,000)$.

Relative maxillary and mandibular positions as represented by ANB angle showed highly significant differences between the Class II, III and Class I control group $(\mathrm{P}=0.000)$. The mean ANB angle were higher in subjects with Class II malocclusion $(7.15 \pm 1.657)$ and the opposite in Class III subjects $(-1.08 \pm$ 2.379). Similar results were obtained by studies of Alice Chin in Chinese population and Denish Raja in Indian population $[13,17]$.

\section{Correlation between cranial base and jaw base measu- rements}

In the present study correlation tests between cranial base angle (NSBa) and SNA in all three groups showed highly significant negative correlation $(r=-.395)(P<0.01)$, i.e. increase in the values of the cranial base angle was accompanied by reduction in SNA angle and vice versa.

This result was coinciding with that of Jarvinen who was first noted the relationship between the maxilla and the cranial base as an increased cranial base angle would lead to a decreased SNA [18].

Similarly, in the present study strong significant negative correlation was also noticed between NSBa and SNB $(r=-.426)$ $(\mathrm{P}<0.01)$. This result would seem reasonable, as increase in the cranial base angle would lead to position the mandible more posteriorly on the posterior cranial base limit.

This finding is in agreement with the studies by Hopkin et al, Kasai et al and Moyers [7,12,19].

However, when the correlation of NSBa to ANB was analyzed, this result was not repeated as no significant correlation was found between these two variables.

The correlation between cranial base angle and jaw lengths was also evaluated in this study, the result showed no significant correlation between NSBa and maxillary and mandibular lengths. This result is in agreement with the result obtained by Denish Raja [14].

\section{Correlation between cranial base length and jaw base measurement}

The sagittal skeletal discrepancy may be caused by an abnormal position of the jaw or insufficient/over jaw growth, leading to an abnormal maxillary- mandibular relation.

Geometrically, the posterior cranial base length particularly- plays a significant role in the sagittal presentations [17].

Various investigators advocated that a longer posterior cranial base can aggravate a sagittal Class II relationship while a shorter base may increase the chance of a Class III relationship $[7,18,20]$.
In this study the linear variable SBa showed significant correlation with SNA $(r=0.323, \mathrm{P}<0.05)$ and SNB $(\mathrm{r}=0.399, \mathrm{P}$ $<0.05$ ) in skeletal Class III group only.

In current study, when correlating SBa to maxillary length, SN and NBa to Maxillary and mandibular length, all groups showed high statistical significance positive correlations ( $\mathrm{P}$ $<0.001$ ). Whereas, for SBa to Mandibular length in Class II and Class III groups no statistically significant relations were found. $(r=.297)(r=.301)$.

It should be noted that the temporo-mandibular joint is positioned at the lateral edges of the cranial base and is, in fact, considerably separated spatially from the midsagittal plane on which cephalometric analyses are based.

Enlow reported that maxillary growth influenced by the growth of the cranial base while the mandible acts in a more independent way owing to its remoteness from the region although its articulation in the glenoid fossa does provide potential for influence from the cranial base [6].

\section{Conclusion}

No significant difference between the mean values for the cranial base angle (NSBa) in different malocclusion groups (I, II, III) also no difference observed in anterior, posterior and total cranial base lengths between Class I, II and III groups.

The SNA and SNB angles decrease as the cranial base angle (NSBa) increases in the three groups, statistically significance positive correlations were found between S-Ba to maxillary length, S-N and N-Ba to Maxillary and mandibular lengths.

\section{References}

1. Young M (1916) A contribution to the study of Scottish skull. Trans R SocEdin 51: 347-453.

2. Brodie AG (1955) The behavior of the cranial base and its components as revealed by serial cephalometric roentgenograms. Angle Orthod 25: 148-160. Link: https://bit.ly/3eHnVQK

3. Björk A (1955) Cranial base development: a follow-up x-ray study of the individual variation in growth occurring between the ages of 12 and 20 years and its relation to brain case and face development. Am J Orthod Dentofacia Orthop 41: 198-225. Link: https://bit.ly/35fHhJO

4. Thiesen G, Pletsch G, Zastrow MD, Martins do Valle CV, do Valle-Corotti MK, et al. (2013) Comparative analysis of the anterior and posterior length and deflection angle of the cranial base, in individuals with facial Pattern I, II and III. Dental Press Journal of Orthodontics 18: 69-75. Link: https://bit.ly/3kklpRE

5. Dhopatkar A, Bhatia S, Rock P (2002) An Investigation into the Relationship between the Cranial Base Angle and Malocclusion. Angle Orthod 72: 456-463. Link: https://bit.ly/32skj02

6. Enlow D (1990) Facial Growth. 3rd ed. Philadelphia: W.B. Saunders.

7. Hopkin G, Houston W, James G (1968) The cranial base as an aetiological factor in malocclusion. Angle Orthod 38: 250-255. Link: https://bit.ly/2JNzpXr

8. Polat Ö, Kaya B (2007) Changes in cranial base morphology in different malocclusions. Orthod Craniofac Res 10: 216-221. Link: https://bit.ly/38A9nRM

9. Houston WJB (1983) The analysis of errors in orthodontic measurements. Am J Orthod 83: 382-390. Link: https://bit.ly/3eLbxz3 
10. Varjanne I, Koski K (1982) Cranial base, sagittal jaw relationship and occlusion A radiological-craniometric appraisal. Proc Finn Dent Soc 78: 179-183. Link: https://bit.ly/3kguydV

11. Bhatia S, Leighton B (1993) A manual of facial growth. Oxford: Oxford University Press. Link: https://bit.ly/38sPcWb

12. Kasai K, Moro T, Kanasawa E, Iwasawa T (1995) Relationship between cranial base and maxillofacial morphology. Eur J Orthod 17: 403-410. Link: https://bit.ly/3n1vwN4

13. de Almeida KC, Raveli TB, Vieira $\mathrm{Cl}$, dos Santos-Pinto A, Raveli DB, et al. (2017) Influence of the cranial base flexion on class I,II and III malocclusion: a systematic review. Press J Orthod 22: 56-66. Link: https://bit.ly/38nxvXY

14. Dinesh R (2017) Relationship of Angular And Linear Measurements Between Cranial Base And Jaw Base in Subjects With Skeletal Class-I, Class-II And Class-III Malocclusion - A Cephalometric Study. Journal of Dental and Medical Sciences (IOSR-JDMS) 16: 63-70. Link: https://bit.ly/36iN5Bq
15. Alves P, Mazuchelli J, Pravin K, Bolognese AM (2008) Cranial base angulation in Brazilian patients seeking orthodontic treatment. J Craniofac Surg 19: 334 338. Link: https://bit.ly/2ImUK9N

16. Kerr W, Adams C (1986) Cranial base and jaw relationship. Am J Phys Anthropol 77: 213-220. Link: https://bit.ly/2IphBI4

17. Chin A, Perry S (2014) The relationship between the cranial base and jaw base in a Chinese population. Head Face Med 10: 31-39. Link: https://bit.ly/38rLZpG

18. Jarvinen S (1980) Relation of the SNA angle to the saddle angle. Am J Orthod 78: 670-673. Link: https://bit.ly/3eJ4gzM

19. Moyers RE (1988) Hand Book of Orthodontics. 4th ed. London: Mosby Publishers. Link: https://bit.ly/2JLqw08

20. Andria LM, Leite L, Prevatte T, Kin L (2004) Correlation of the cranial base angle and its components with other dental/skeletal variables and treatment time. Angle Orthod 74: 361-366. Link: https://bit.ly/35fukj1

\section{Discover a bigger Impact and Visibility of your article publication with}

\section{Peertechz Publications}

\section{Highlights}

* Signatory publisher of ORCID

* Signatory Publisher of DORA (San Francisco Declaration on Research Assessment)

* Articles archived in worlds' renowned service providers such as Portico, CNKI, AGRIS, TDNet, Base (Bielefeld University Library), CrossRef, Scilit, J-Gate etc.

* Journals indexed in ICMJE, SHERPA/ROMEO, Google Scholar etc.

- OAI-PMH (Open Archives Initiative Protocol for Metadata Harvesting)

* Dedicated Editorial Board for every journa

* Accurate and rapid peer-review process

* Increased citations of published articles through promotions

- Reduced timeline for article publication

Submit your articles and experience a new surge in publication services (https://www.peertechz.com/submission).

Peertechz journals wishes everlasting success in your every endeavours.

Copyright: $\odot 2020$ Elgadir Ahmed AA, et al. This is an open-access article distributed under the terms of the Creative Commons Attribution License, which permits unrestricted use, distribution, and reproduction in any medium, provided the original author and source are credited. 